\title{
ATIVIDADE ANTIFÚNGICA DE EXTRATOS BRUTOS DE Ottonia martiana Miq., Piperaceae.
}

\section{ANTIFUNGAL ACTIVITY OF CRUDE EXTRACTS OF Ottonia martiana Miq., Piperaceae.}

CUNICO, M. M. ${ }^{1}$; CARVALHO, J. L. S. ${ }^{1}$; ANDRADE, C. A. ${ }^{1}$; MIGUEL, O. G. ${ }^{1 *}$; MIGUEL, M. D. ${ }^{1}$; AUER, C. G. ${ }^{2}$; GRIGOLETTI JÚNIOR, A. ${ }^{2}$; CÔCCO, L. C. ${ }^{3}$; YAMAMOTO, C. I. ${ }^{3}$

${ }^{1}$ Laboratório de Fitoquímica, Departamento de Farmácia, Universidade Federal do Paraná.

Av. Prefeito Lothário Meissner, $n^{0}$ 632, CEP: 80210170 - Jardim Botânico, CuritibaParaná, Brasil."E-mail: obdulio@ufpr.br

${ }^{2}$ Laboratório de Fitoapatologia, Embrapa Florestas, Colombo, Paraná, Brasil. ${ }^{3}$ Laboratório de Combustíveis Automotivos (LACAUT), Universidade Federal do Paraná, CP 19081, 81531-990 Curitiba - PR, Brasil.

\section{RESUMO}

A produção de alimentos orgânicos baseia-se em produtos naturais ou extratos de plantas para o controle de pragas e doenças. A busca por produtos naturais é um trabalho constante para que haja uma grande variedade à disposição dos produtores rurais, uma vez que não é permitido o emprego de fungicidas sintéticos para o cultivo de espécies medicinais utilizados nas indústrias de fitoterápicos assim como de alimentos. Este estudo objetivou a atividade antifúngica de extratos brutos etanólicos e aquosos de Ottonia martiana contra os fitopatógenos Fusarium oxysporum, Colletotrichum acutatum, Rhizoctonia sp. Avaliou-se o efeito dos extratos sobre o crescimento micelial in vitro. Verificou-se a redução do crescimento micelial de todos os fungos e a maior atividade foi produzida pelo extrato bruto etanólico das raízes de $O$. martiana.

Palavras-chave: controle altenartivo, patógeno de planta, planta medicinal.

\footnotetext{
${ }^{1}$ Departamento de Farmácia, Laboratório de Fitoquímica, Universidade Federal do Paraná.

2 Embrapa Florestas, Colombo, Paraná, Brasil.

${ }^{3}$ LACAUT, Universidade Federal do Paraná, CP 19081, 81531-990 Curitiba - PR, Brasil.
} 


\section{ABSTRACT}

The production of organic food is based either on natural products or plant extracts for disease and pest control. Search for natural products is constant work in order to fournish a huge variety for rural producers. The objective of ths study was to test antifungal potential of crude extracts of Ottonia martiana (ethanolic and aqueous) against Fusarium oxysporum, Colletotrichum acutatum, Rhizoctonia sp. The action of these extracts causing inhibition on mycelial growth was evaluated in vitro. It was verified reduction of growth in all fungi and high activity was produced by ethanolic roots extract.

Key words : alternative control, medicinal plant, plant pathogen.

\section{INTRODUÇÃO}

O uso contínuo e incorreto dos agrotóxicos tem causado sérios problemas ambientais (CAMPANHOLA; BETTIOL, 2003; CUNICO et al., 2003). Outro aspecto a ser levantado é a produção orgânica de alimentos que necessita de produtos naturais e extrato de plantas para o controle de doenças e de pragas agrícolas.

Os extratos de plantas medicinais apresentam características antimicrobianas interessantes ao homem, o qual as utiliza comumente para controlar ou abreviar os sintomas de doenças humanas. No caso de fitopatógenos, alguns desses extratos são também úteis como antifúngicos (SCHWAN-ESTRADA et al., 2000). Também, esta forma de controle alternativo é interessante aos produtores rurais pela facilidade de acesso às plantas medicinais, normalmente cultivadas nas pequenas propriedades agrícolas.

Pelo exposto, este trabalho teve por objetivo realizar uma investigação do potencial antifúngico dos extratos da espécie vegetal Ottonia martiana, arbusto da Floresta Atlântica e conhecida pelos nativos do Litoral Paranaense como "Anestésia" devido a sua propriedade anestésico local na mucosa oral humana (LOPES, 1989; CUNICO et al., 2004; CUNICO et al., 2005; CUNICO et al., 2006) contra alguns fitopatógenos de plantas. 


\section{MATERIAL E MÉTODOS}

\subsection{INSTRUMENTAÇÃO E MATERIAL}

Os solventes e reagentes utilizados apresentavam grau de pureza P.A. (Merck). Os isolados dos patógenos testados foram fornecidos pelo Centro de Diagnóstico Marcos Enrietti, da Secretaria de Agricultura do Estado do Paraná e pelo Laboratório de Fitopatologia da EMBRAPA Florestas. Os isolados foram obtidos de plantas de café (Fusarium oxysporum), de morango (Colletotrichum acutatum) e de erva-mate (Rhizoctonia sp.). O teor alcoólico dos extratos foi analisado pelo método da microdiluição. As análises cromatográficas foram realizadas por CLAE Shimadzu, modelo LC-6A, com detector UV modelo SPD-6AV e coluna Shimadzu Shim pack prep-ODS.

\subsection{MATERIAL VEGETAL}

Raízes e partes aéreas de O. martiana, foram coletadas em abril de 2000, em Coroados, no Município de Guaratuba (encosta da Floresta Atlântica - Serra do Mar), no Estado do Paraná, a uma altitude de 20 metros. A identificação da espécie vegetal foi realizada pelo Botânico Dr. Gerdt Hatschbach do Museu Botânico Municipal (MBM), da Prefeitura de Curitiba-PR, e um exemplar desta espécie (exsicata), foi depositado no Herbário deste Museu, registrado sob número 259.057.

\subsection{OBTENÇÃO DOS EXTRATOS VEGETAIS}

Isoladamente, caules (116,05 g) e raízes (67,56 g) da espécie em estudo foram triplamente macerados em etanol (95\%), concentrados a pressão reduzida (40 ${ }^{\circ} \mathrm{C}$ ) a aproximadamente 1/5 do seu volume, armazenados em frasco âmbar após precipitação da porção lipofílica em freezer por um período de 24 horas e filtração a vácuo.

O extrato bruto aquoso (EBaquoso) das folhas frescas (15 g) de O. martiana, foi obtido após a droga vegetal ser triturada no liqüidificador com água destilada (um minuto) seguido de filtração em funil de vidro sinterizado sob vácuo.

Antes da autoclavagem, o pH das soluções contendo extratos encontrava-se em torno de 5,5 (extratos etanólicos) e 6,4 (extrato aquoso), respectivamente. 


\subsection{ENSAIO BIOLÓGICO}

Inicialmente, fez-se um teste de antagonismo entre os fitopatógenos pelo método da cultura pareada, ou simplesmente pareamento, que consistiu no confronto direto do antagonista e dos fitopatógenos (interação fungo-fungo-fungo) em placas de Petri contendo meio de cultura sólido BDA (adaptado de MARIANO, 1993). Em seguida, 48 horas após o meio BDA ter sido vertido em placas de Petri, 3 discos de micélio com $5 \mathrm{~mm}$ de diâmetro, um de cada patógeno testado, foram colocados de forma diamentralmente opostos na placa. A seguir, as placas foram incubadas a $25^{\circ} \mathrm{C}$ no escuro, após vedação com filme plástico. $O$ tratamento controle continha apenas o meio BDA.

Para verificar a inibição do crescimento micelial frente aos extratos de $O$. martiana, extratos brutos etanólicos (caules e raízes) e aquoso (folhas frescas) foram incorporados separadamente em meio de cultivo BDA (Batata-Dextrose-Ágar), cada um nas concentrações de 50, 25 e 12,5 \% (em relação ao BDA), e, autoclavados a $120^{\circ} \mathrm{C}$, a 1 atm por 15 minutos. O meio BDA contendo extrato foi vertido em placas de Petri $(15 \mathrm{~cm}$ de diâmetro) e após uma hora de resfriamento, 3 discos de micélio de $5 \mathrm{~mm}$ de diâmetro, um de cada fitopatógeno testado, foram colocados de forma diamentralmente opostos na placa.de Petri. Os isolados F. oxysporum, C. acutatum e Rhizoctonia sp., foram retirados de culturas puras com 7 dias de idade em meio BDA. A seguir, as placas foram incubadas a $25^{\circ} \mathrm{C}$ no escuro, após vedação com filme plástico. $\mathrm{O}$ tratamento controle continha apenas o meio BDA. As avaliações foram realizadas por meio de medições do diâmetro das colônias (média de duas medidas perpendiculares), após cinco dias de incubação dos patógenos, ou no momento em que as colônias fúngicas do tratamento controle atingissem aproximadamente a superfície total do meio de cultura.

O delineamento experimental foi inteiramente casualizado com 6 repetições. $\mathrm{Na}$ análise estatística dos resultados obtidos, empregou-se o Teste de Tukey com limite de confiança de $95 \%$, utilizando-se o programa SANEST (ZONTA; MACHADO; SILVEIRA, 1984). 


\subsection{ANÁLISE POR CLAE}

Parte do EBaquoso (folhas frescas) foi autoclavado e comparado ao EBaquoso não autoclavado numa análise por CLAE. Os extratos também foram comparados com amostras autênticas das amidas bioativas isopiperlonguminina e piperovatina.

As condições de análise das amostras foram as seguintes: fase móvel constituída dos solventes $A$, B e C (A: $\mathrm{H}_{3} \mathrm{PO}_{4}$ 0,1\%+0,12 $\mathrm{N} \mathrm{H}_{2} \mathrm{SO}_{4}$; $\mathrm{B}$ : $\mathrm{MeOH}$ e $\mathrm{C}$ : $\left.\mathrm{ACN}\right)$, fluxo de $1,0 \mathrm{~mL} \mathrm{~min}^{-1}$, volume injetado da amostra de $20 \mu \mathrm{L}$, comprimento de onda (I) igual a 280 $\mathrm{nm}$. Todas as análises foram realizadas em triplicata.

\section{RESULTADOS E DISCUSSÃO}

Os dados obtidos por meio do método da cultura pareada permitiram comprovar que os fungos presentes na mesma placa de Petri não sofreram antagonismo, quando comparados aos cultivados isoladamente nas placas de Petri. O extrato bruto etanólico (EBEtOH) das raízes apresentou maior atividade antifúngica, causando inibição do crescimento dos três patógenos acima de 50 \%. O extrato bruto aquoso (EBaquoso) das folhas frescas apresentou maior atividade na inibição do crescimento da Rhizoctonia sp. O efeito inibitório dos EBEtOH ensaiados frente a $C$. acutatum não foi dependente da concentração utilizada. Estes resultados podem ser visualizados na TABELA I, a seguir. 
TABELA I - EFEITO DA CONCENTRAÇÃO DOS EXTRATOS BRUTOS ETANÓLICOS (CAULES E RAÍZES) E AQUOSO (FOLHAS FRESCAS) DE O. martiana, SOBRE O CRESCIMENTO MICELIAL (mm) DOS PATÓGENOS TESTADOS

\begin{tabular}{|c|c|c|c|c|c|c|c|}
\hline \multirow{3}{*}{ AMOSTRA } & \multirow{3}{*}{$\begin{array}{l}\text { Concentração } \\
\text { do EB em BDA } \\
(\%=\mathrm{mg})\end{array}$} & \multicolumn{6}{|c|}{$\begin{array}{l}\text { Média dos Halos de Crescimento Micelial dos } \\
\text { isolados } \\
(\mathrm{mm})\end{array}$} \\
\hline & & \multicolumn{2}{|c|}{$\begin{array}{c}\text { Fusarium } \\
\text { oxysporum }\end{array}$} & \multicolumn{2}{|c|}{$\begin{array}{c}\text { Colletotrichum } \\
\text { acutatum }\end{array}$} & \multicolumn{2}{|c|}{ Rhizoctonia sp. } \\
\hline & & $\overline{\text { EB }}$ & \begin{tabular}{|c|}
$\begin{array}{c}\text { Controle } \\
\text { A/B }\end{array}$ \\
\end{tabular} & EB & \begin{tabular}{|c|} 
Controle \\
A/B
\end{tabular} & $\overline{\text { EB }}$ & $\begin{array}{c}\text { Controle } \\
\text { A/B }\end{array}$ \\
\hline $\begin{array}{l}\text { EBEtOH } \\
\text { (raízes) }\end{array}$ & $\begin{array}{l}50,0 \%=102,2 \\
25,0 \%=51,1 \\
12,5 \%=25,5\end{array}$ & $\begin{array}{l}2,3 \mathrm{a} \\
2,7 \mathrm{a} \\
2,7 \mathrm{a}\end{array}$ & $\begin{array}{r}6,1 \mathrm{~b} / \\
6,0 \mathrm{~b}\end{array}$ & $\begin{array}{l}1,6 \mathrm{c} \\
1,8 \mathrm{c} \\
2,5 \mathrm{a}\end{array}$ & $\begin{array}{l}5,4 \mathrm{~d} / \\
5,5 \mathrm{~d}\end{array}$ & $\begin{array}{l}2,0 \mathrm{a} \\
2,1 \mathrm{a} \\
2,4 \mathrm{a}\end{array}$ & $\begin{array}{l}7,2 \mathrm{e} / \\
7,0 \mathrm{e}\end{array}$ \\
\hline $\begin{array}{l}\text { EBEtOH } \\
\text { (caules) }\end{array}$ & $\begin{array}{l}50,0 \%=1335,0 \\
25,0 \%=667,8 \\
12,5 \%=333,9\end{array}$ & $\begin{array}{l}2,7 \mathrm{a} \\
3,2 \mathrm{a} \\
3,6 \mathrm{a}\end{array}$ & $\begin{array}{r}6,1 \mathrm{~b} / \\
6,0 \mathrm{~b}\end{array}$ & $\begin{array}{l}3,0 \mathrm{a} \\
2,7 \mathrm{a} \\
3,7 \mathrm{a}\end{array}$ & $\begin{array}{l}5,4 \mathrm{~d} / \\
5,5 \mathrm{~d}\end{array}$ & $\begin{array}{l}2,6 \mathrm{a} \\
2,7 \mathrm{a} \\
2,7 \mathrm{a}\end{array}$ & $\begin{array}{l}7,2 \mathrm{e} / \\
7,0 \mathrm{e}\end{array}$ \\
\hline $\begin{array}{l}\text { EBaquoso } \\
\text { (folhas } \\
\text { frescas) }\end{array}$ & $\begin{array}{l}50,0 \%=810,0 \\
25,0 \%=405,0 \\
12,5 \%=202,5\end{array}$ & $\begin{array}{l}5,8 \text { b } \\
6,2 \text { b } \\
6,1 \text { b }\end{array}$ & $\begin{array}{r}6,0 \mathrm{~b} / \\
6,0 \mathrm{~b}\end{array}$ & $\begin{array}{l}4,7 f \\
4,4 f \\
4,7 f\end{array}$ & $\begin{array}{l}4,8 \mathrm{f} / \\
4,5 \mathrm{f}\end{array}$ & $\begin{array}{l}1,5 \mathrm{c} \\
2,5 \mathrm{a} \\
5,5 \mathrm{~b}\end{array}$ & $\begin{array}{l}6,5 \mathrm{~b} / \\
6,0 \mathrm{~b}\end{array}$ \\
\hline
\end{tabular}

Médias seguidas de mesma letra não diferem estatisticamente entre si (Tukey $-P<0,05)$. Cada valor é média de 6 repetições.

Controle A: controle com inóculos dos patógenos pareados em meio BDA.

Controle B: controle com inóculos dos patógenos colocados isoladamente nas placas de Petri em meio BDA.

Uma visão dos resultados deste ensaio pode ser tomada com base na Figura 1, a seguir. 
FIGURA 1 - VISUALIZAÇÃO DO CRESCIMENTO MICELIAL DOS FITOPATÓGENOS TESTADOS:

1 - Fusarium oxysporum / 2 - Colletotrichum acutatum / 3 - Rhizoctonia sp.
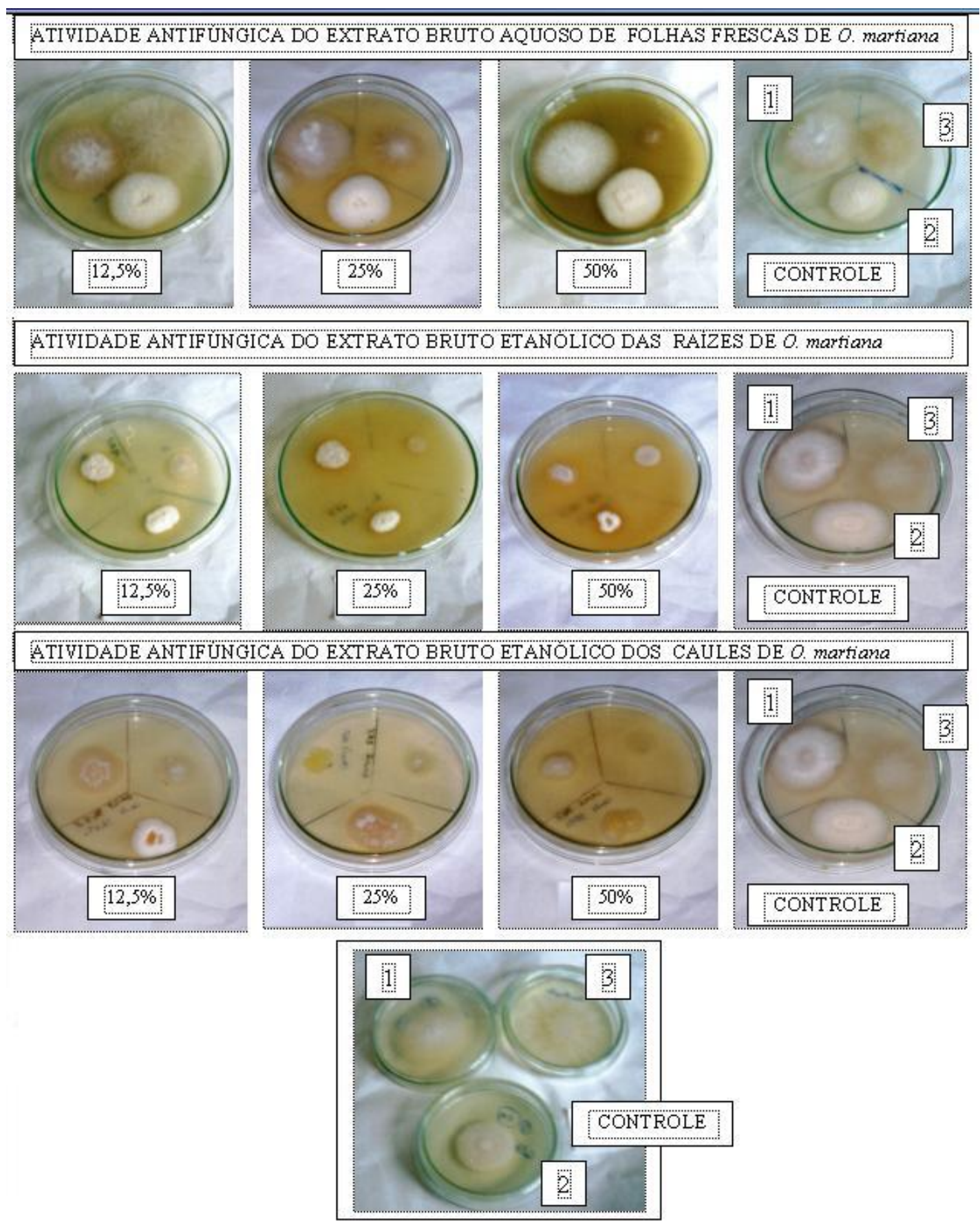
$\mathrm{Na}$ Tabela II, podem-se visualizar os dados de inibição do crescimento micelial dos isolados dos patógenos testados em porcentagem.

TABELA II - ATIVIDADE FUNGITÓXICA DOS EBEtOH (CAULES E RAÍZES) E EBaquoso (FOLHAS FRESCAS) DE O. martiana, NO CRESCIMENTO DE TRÊS FITOPATÓGENOS

\begin{tabular}{|c|c|c|c|c|}
\hline \multirow{2}{*}{ AMOSTRA } & \multirow[b]{2}{*}{$\begin{array}{c}\text { Concentração } \\
\text { do extrato em } \\
\text { BDA }\end{array}$} & \multicolumn{3}{|c|}{ INIBIÇÃO DO CRESCIMENTO MICELIAL (\%) } \\
\hline & & $\begin{array}{l}\text { Fusarium } \\
\text { oxysporum }\end{array}$ & $\begin{array}{c}\text { Colletotrichum } \\
\text { acutatum }\end{array}$ & $\begin{array}{c}\text { Rhizoctonia } \\
\text { sp. }\end{array}$ \\
\hline $\begin{array}{l}\text { EBEtOH } \\
\text { (raízes) }\end{array}$ & $\begin{array}{c}50,0 \%=102,2 \\
\mathrm{mg} \\
25,0 \%=51,1 \\
\mathrm{mg} \\
12,5 \%=25,5 \\
\mathrm{mg}\end{array}$ & $\begin{array}{l}62,30^{\star} \\
55,74 \\
55,74\end{array}$ & $\begin{array}{l}66,67 \\
70,37 \\
53,70\end{array}$ & $\begin{array}{l}72,22 \\
70,83 \\
66,67\end{array}$ \\
\hline $\begin{array}{l}\text { EBEtOH } \\
\text { (caules) }\end{array}$ & $\begin{array}{c}50,0 \%=1335,0 \\
m g \\
25,0 \%=667,8 \\
m g \\
12,5 \%=333,9 \\
m g\end{array}$ & $\begin{array}{l}55,74 \\
47,54 \\
40,98\end{array}$ & $\begin{array}{l}44,45 \\
50,00 \\
31,48\end{array}$ & $\begin{array}{l}63,89 \\
62,50 \\
62,50\end{array}$ \\
\hline $\begin{array}{c}\text { EBaquoso } \\
\text { (folhas } \\
\text { frescas) }\end{array}$ & $\begin{array}{c}50,0 \%=810,0 \\
\mathrm{mg} \\
25,0 \%=405,0 \\
\mathrm{mg} \\
12,5 \%=202,5 \\
\mathrm{mg}\end{array}$ & $\begin{array}{l}3,33 \\
0,00 \\
0,00\end{array}$ & $\begin{array}{l}8,33 \\
4,17 \\
2,08\end{array}$ & $\begin{array}{l}76,92 \\
61,54 \\
15,39\end{array}$ \\
\hline
\end{tabular}

*Dados obtidos por comparação das médias das colônias fúngicas do tratamento com a testemunha. 
O teor alcoólico dos extratos etanólicos analisados por microdestilação foi considerado desprezível visto ser inferior a 0,01 \% (0,007 \% para o EBEtOH das raízes e $0,009 \%$ para o EBEtOH dos caules). Estes dados sugerem que o etanol não causa interferência na atividade antifúngica evidenciada neste trabalho.

$\mathrm{Na}$ análise por CLAE dos EBaquosos não autoclavado e autoclavado (folhas frescas), uma possível hidrólise de substâncias foi evidenciada, entretanto, quando estes foram comparados com amostras autênticas de amidas comprovadamente presentes nestes extratos (Isopiperlonguminina e Piperovatina), alterações não foram exibidas (FIGURAS 2 e 3).

A inibição do crescimento micelial foi mais acentuada em Rhizoctonia sp. Como este patógeno ataca um grande número de culturas agrícolas (SMITH et al., 1992), estudos sobre o uso do extrato de $O$. martiana poderia ser melhor aprofundado para controlar o tombamento de mudas e queimas foliares em mudas de espécies florestais. $\mathrm{O}$ uso do extrato reduziria a utilização de agrotóxicos de forma a diminuir o impacto ambiental decorrente da ação dos produtos químicos em organismos não alvos, além disso, visto não ser permitido, impediria o emprego dos mesmos no cultivo de espécies medicinais utilizadas como matéria-prima na indústria de fitoterápicos (CAMPANHOLA; BETTIOL, 2003). 
FIGURA 2 - PERFIL CROMATOGRÁFICO (CLAE):

1 - EXT.RATO BRUTO AQUOSO DAS FOLHAS (FRESCAS) NÃO AUTOCLAVADO

2 - EXTRATO BRUTO AQUOSO DAS FOLHAS (FRESCAS) AUTOCLAVADO

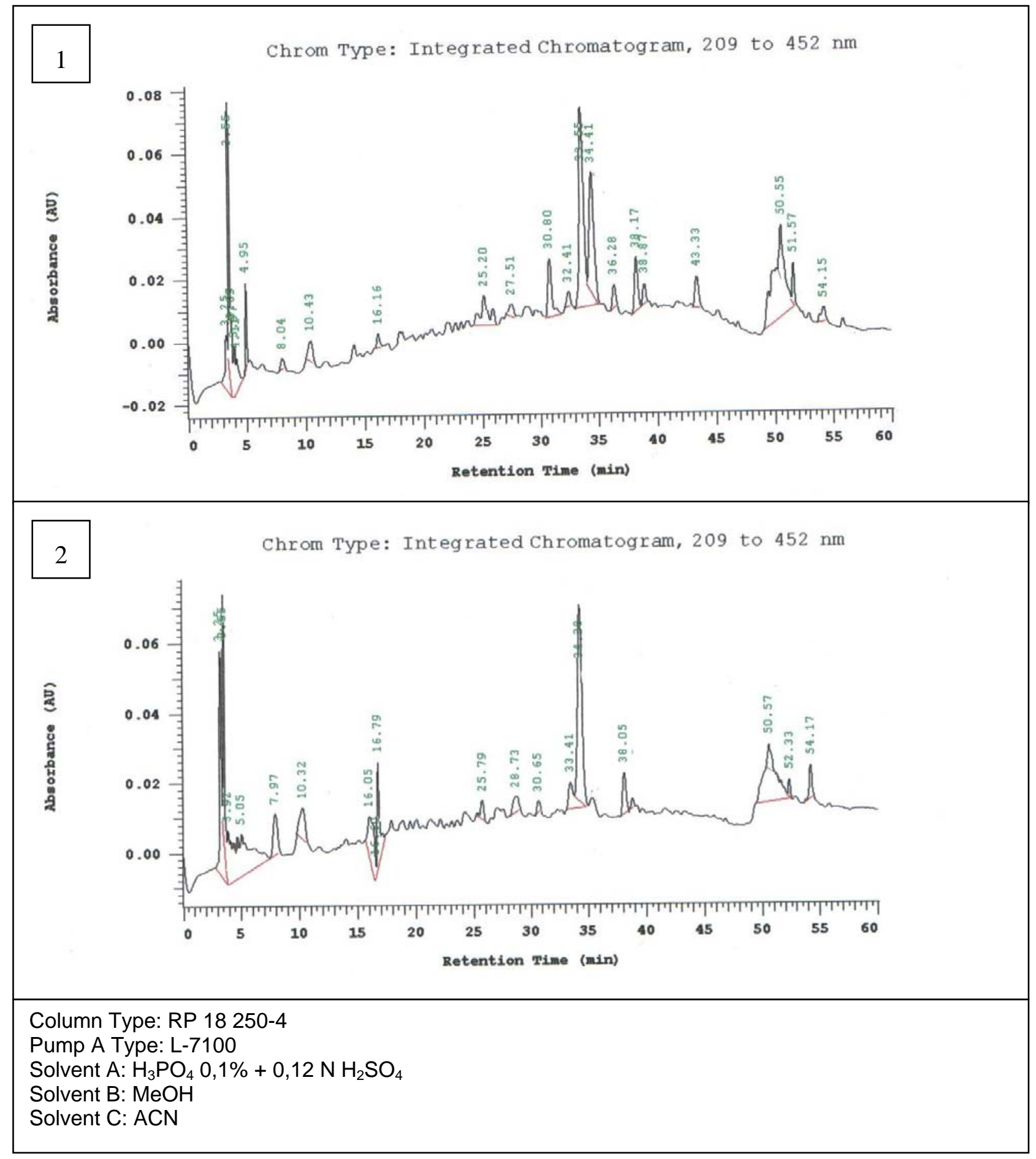


FIGURA 3 - PERFIL CROMATOGRÁFICO (HPLC):

A - PADRÃO: ISOPIPERLONGUMININA

B - PADRÃO: PIPEROVATINA

C - A + B + 1(extrato não autoclavado) +2 (extrato autoclavado)

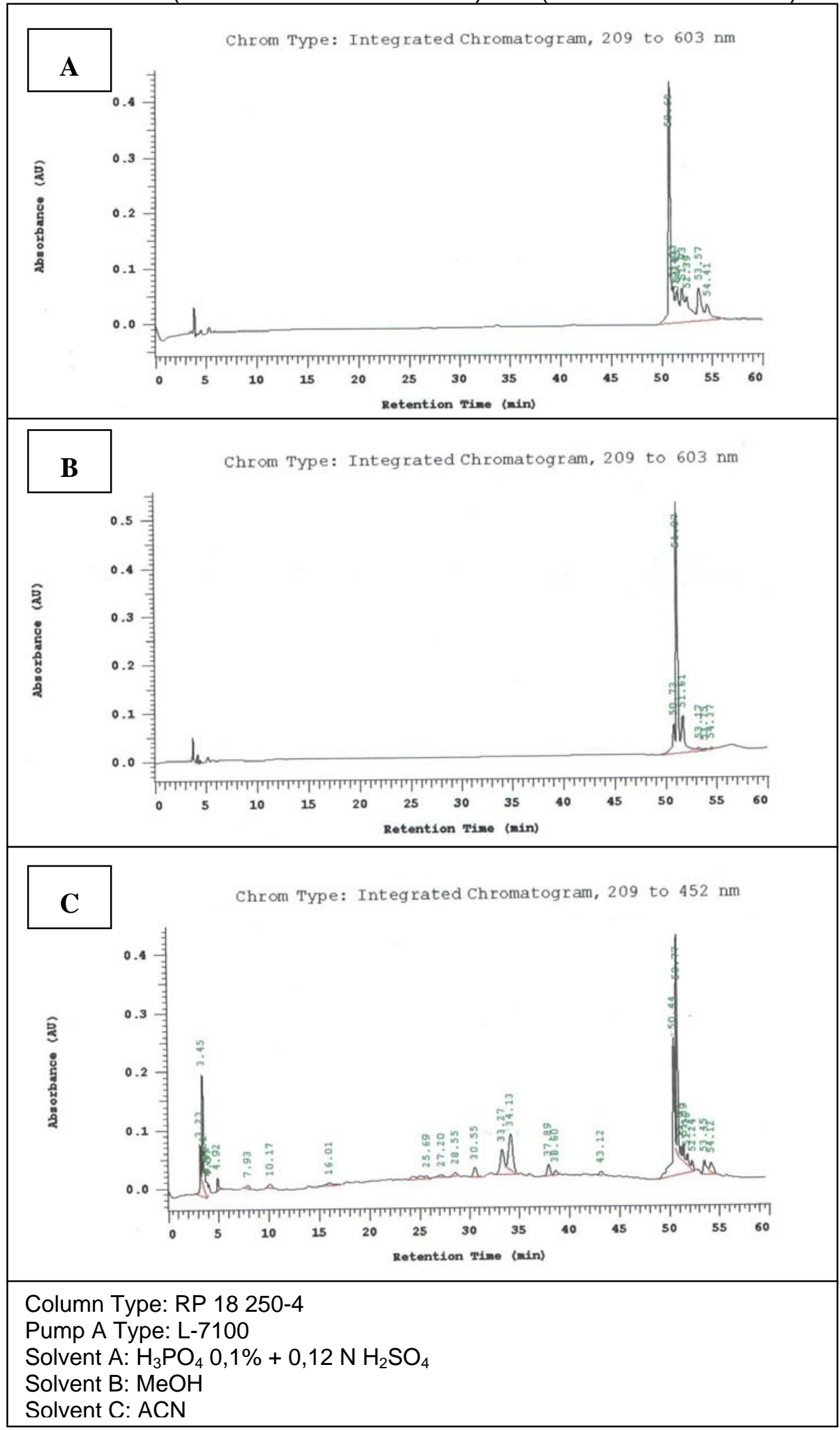




\section{CONCLUSÃO}

O método de pareamento utilizado mostrou ausência de antagonismo entre os microrganismos testados.

O potencial antifúngico de extratos da O. martiana foi confirmado contra $F$. oxysporum, C. acutatum e Rhizoctonia sp. neste bioensaio. Houve uma maior atividade dos extratos contra Rhizoctonia sp. in vitro, indicando a necessidade de testes de controle em condições de campo.

Esta pesquisa reafirma a necessidade de se investir na busca de novos métodos alternativos no controle de fitopatógenos, ambientalmente corretos, sem danos ao meio ambiente e à saúde humana.

\section{AGRADECIMENTOS}

À CNPq pelo suporte financeiro. Ao Dr. Gerdt Hatschbach do MBM, pela identificação da espécie vegetal. Aos coletores Osmar S. Ribas e Valdir A. Pereira do $\operatorname{MBM}\left(n^{\circ} 3633\right)$, pelo material vegetal.

\section{REFERÊNCIAS}

CAMPANHOLA, C.; BETTIOL, W. Panorama sobre o uso de agrotóxicos no Brasil. In: CAMPANHOLA, C.; BETTIOL, W. (ed.). Métodos alternativos de controle fitossanitário. Jaguariúna> Embrapa Meio Ambiente, P. 13-51, 2003.

CUNICO, M. M.; MIGUEL, O. G.; MIGUEL, M. D.; PEITZ, C.; AUER, C. G.; GRIGOLETTI JÚNIOR, A. Estudo da atividade antifúngica de Ottonia martiana Miq., Piperaceae: Um teste in vivo. Revista Visão acadêmica, v.4, n.2, p.77-82, 2003

CUNICO, M. M. ; MIGUEL, M. D. ; KERBER, V. A. ; SBOLLI, K. C. ; MIGUEL, O. G. Ottonia martiana Miq.: Estudo in vivo da irritação da mucosa oral. Visão Acadêmica, Curitiba-PR, v. 5, n. 2, p. 147-150, 2004.

CUNICO, M. M. ; CARVALHO, J. L. S. ; AUER, C. G. ; GRIGOLLETI JUNIOR, A. ; MONACHE, F. D. ; MIGUEL, M. D. ; MIGUEL, O. G. . Gênero Ottonia: uma revisão das principais características botânicas, fitoquímicas e biológicas. Revista Brasileira de Plantas medicinais, v. 7, n. 2, p. 17-21, 2005.

CUNICO, M. M.; DIAS, J. F. D.; MIGUEL, M. D.; MIGUEL, O. G.; AUER, C. G. ; CÔCCO, C. L.; FERREIRA, J.; LOPES, A. R. Potencial antimicrobiano e alelopático das amidas 
isoladas do extrato das raízes de Ottonia martiana Miq. Química Nova, v.29, n.4, p.746749, 2006.

LOPES, M. Contribuição para o Estudo Fitoquímico de Ottonia martiana Miq. Piperaceae. Curitiba, 1989. 102 f. Dissertação (Mestrado em Botânica), Setor de Ciências Biológicas, Universidade Federal do Paraná.

MARIANO, R. L. R. Métodos de seleção in vitro para o controle microbiológico de patógenos de plantas. Revisão Anual de Patologia de Plantas. EMBRAPA - CNPTrigo, Brasília, v.1, p. 369-409, 1993.

SCHWAN-ESTRADA, K.R.F.; STANGARLIN, J.R.; CRUZ, M.E. da S. Uso de extratos vegetais no controle de fungos fitopatogênicos. Floresta, Curitiba, n. 1/2, p. 129-137, 2000.

SMITH, I.M.; DUNEZ, J.; LELLIOT, R.A.; PHILIPS, D.H.; ARCHER, S.A. Manual de enfermedades de las plantas. Madrid: Ediciones Mundi Prensa, 1992. $671 \mathrm{p}$.

ZONTA, E. P.; MACHADO, A. A.; SILVEIRA JÚNIOR, P. Sistema de Análise Estatística para Microcomputadores (SANEST). Pelotas, RS. UFPEL, 1984. Programa Estatístico para Microcomputadores. 